\title{
Biophysical Analysis of the Endoplasmic Reticulum-Resident Chaperone/Heat Shock Protein gp96/GRP94 and Its Complex with Peptide Antigen ${ }^{\dagger}$
}

\author{
Nora A. Linderoth, ${ }^{\ddagger}$ Martha N. Simon,${ }^{\S}$ Natalia A. Rodionova, ${ }^{\ddagger}$ Martine Cadene,${ }^{\ddagger}$ William R. Laws,"

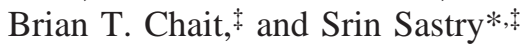 \\ Laboratory of Molecular Genetics, Laboratory of Molecular Biophysics, and Laboratory of Mass Spectrometry and \\ Chemical Physics, The Rockefeller University, 1230 York Avenue, New York, New York 10021, Department of Biology, \\ Brookhaven National Laboratory, Upton, New York 11973, and Department of Biochemistry and Molecular Biology, \\ Mount Sinai School of Medicine, One Gustave L. Levy Place, New York, New York 10029
}

Received July 12, 2000; Revised Manuscript Received October 4, 2000

\begin{abstract}
Animals vaccinated with heat shock protein (HSP)-peptide complexes develop specific protective immunity against cancers from which the HSPs were originally isolated. This autologous specific immunity has been demonstrated using a number of HSP-peptide antigen complexes. A prototypical HSP-based cancer vaccine is the gp96-peptide antigen complex, which is currently undergoing human clinical trials. Here, we analyzed the structure of a recombinant wild-type and a mutant gp96 protein and their peptide complexes using a number of biophysical techniques. Gel filtration chromatography, dynamic light scattering, and equilibrium analytical ultracentrifugation demonstrated that both a wild-type gp96 and a gp96 mutant lacking a dimerization domain formed higher order structures. More detailed analysis using scanning transmission electron microscopy indicated that both the wild-type and dimerization deletion mutant gp96 protein were organized, unexpectedly, into large aggregates. Size distributions ranged from dimers to octamers and higher. Circular dichroism and intrinsic Trp fluorescence suggested that the gp96 dimerization domain deletion mutant protein was more compact than the wild-type gp96. A fluorescent peptide antigen was synthesized, and the peptide-binding properties of wild-type and the dimerization domain deletion mutant gp96 were studied. Fluorescence lifetime and anisotropy decay showed that the bound antigenic peptide was located in a hydrophobic pocket, with considerable free space for the rotation of the probe. Deletion of the dimerization domain affected the peptide-binding microenvironment, although peptide-binding affinity was reduced by only a small extent. Peptide-gp96 complexes were extremely stable, persisting for many days in the cold. The extraordinary stability of peptide-gp96 complexes and the plasticity of the peptide-binding pocket support the proposed relay of diverse peptides to MHC and/or other molecules via molecular recognition.
\end{abstract}

Proper functioning of the immune system requires constant surveillance and evaluation of the peptide repertoire in cells and tissues. Peptide antigens of endogenous and exogenous origins are loaded on to major histocompatibility complex $(\mathrm{MHC})^{1}$ class I and class II molecules, respectively, and are displayed on the surfaces of antigen-presenting cells such as macrophages or dendritic cells (e.g., see ref 1). In turn, these antigen-presenting cells stimulate antigen-specific $\mathrm{CD}^{+}$(class I) and $\mathrm{CD}^{+}$(class II) lymphocytes (reviewed in $(2-4)$ ). A large body of experimental evidence stemming

\footnotetext{
$\doteqdot$ This work was supported in part by grants from the Cancer Research Institute, New York, Antigenics LLC, New York, and the Hewlett-Packard Foundation to S.S. M.N.S. was supported by grants from the National Institutes of Health (P41-RR01777) and from the U.S. Department of Energy Office of Biological and Environmental Research. W.R.L. was supported in part by an Instrumentation Development Grant, DBI-9724330, from the National Science Foundation.

* To whom correspondence should be addressed. Laboratory of Molecular Genetics, Box 174, The Rockefeller University, 1230 York Ave, New York, NY 10021. Telephone: 212-327-8987. Fax: 212327-8651. E-mail: sastrys@ rockvax.rockefeller.edu.

The Rockefeller University.

$\S$ Brookhaven National Laboratory.

"Mount Sinai School of Medicine.
}

from tumor immunology suggests that peptide-binding heat shock/stress proteins (HSPs) of the endoplasmic reticulum (ER) and cytosol participate, in some cases, in the presentation of peptide antigens to the immune system (for reviews, see refs 5 and 6 ). The most compelling evidence for the interface of the heat shock/stress response with the immune defense system comes from studies of the ER glycoprotein gp96/GRP94.

gp96/GRP94 is a member of the HSP90 family. The HSPs, also known as molecular chaperones, are ubiquitous in nature and participate in a variety of cellular processes such as protein folding, stabilization, oligomeric assembly, transport, and degradation $(7,8)$. HSPs are upregulated in response to cellular stresses such as heat shock, cancer, and infection but are also vital during normal growth. Certain HSPs, most

\footnotetext{
${ }^{1}$ Abbreviations: $\mathrm{CD}$, circular dichroism; DDD, dimerization domain deletion; ER, endoplasmic reticulum; HSP, heat shock/stress protein; 4-HCCA, $\alpha$-cyano-4-hydroxy cinnamic acid; MALDI-TOF MS, matrix-assisted laser desorption-time-of-flight mass spectrometry; MHC, major histocompatibility complex; pyr, pyrene; $r(t)$, time-resolved fluorescence anisotropy; ss, single-stranded; STEM, scanning transmission electron microscopy; TAP, transporter associated with antigen processing; TFA, trifluoroacetic acid; WT, wild-type gp96.
} 
notably gp96/GRP94, but also HSP70, HSP90, and calreticulin, bind peptides and appear to stimulate immune responses against cancers and infectious agents by making their peptide cargo available to the immune system $(5,9$, 10). Immunization with gp96-peptide complexes isolated from tumor- $(11,12)$ or virus-infected cells $(13,14)$, or reconstituted in vitro (15), elicits specific protective immunity to bound peptides but not to gp96 itself. Immunoprotection is MHC class I-dependent and mediated by $\mathrm{CD} 8^{+} \mathrm{T}$ lymphocytes $(16-18)$. These and other studies indicate that gp96 chaperones a broad range of peptides found in cells. Receptor-mediated internalization of gp96-peptide complexes has recently been demonstrated $(19,20,62)$. It has yet to be determined how the gp96-bound peptides are relayed to MHC class I molecules.

Peptide binding by gp96 has been studied with interest because its tumor rejection potency depends on bound peptides (reviewed in ref 21). gp96 binds a variety of short peptides with sizes ranging from 4-mers to 40-mers $(13,22-$ 29). In vitro stable peptide binding by gp96 can occur in the absence of other proteins and is adenosine triphosphate (ATP)-independent. In vivo gp96 receives peptides transported into the ER by a transporter associated with antigen processing (TAP; 23, 30, 31). However, TAP-independent association of peptides with gp96 has also been reported (30). Very little information is known about the structure of gp96 and its complexes with peptides because there are no crystallographic or NMR-derived models. On the basis of limited proteolysis, it was proposed that gp96 was organized into higher order complexes (principally dimers) via a C-terminal dimerization domain (32). We have recently shown that peptide binding by gp96 requires a region in the C-terminal third of the protein that abuts the proposed dimerization domain (29). Here, we examine the role of the proposed dimerization domain in the higher order quaternary structure of gp96 and explore the relationship, if any, between multimerization and peptide binding. Surprisingly, we find that gp96 appears to be organized into larger multimeric complexes than previously thought and that the dimerization domain itself plays a smaller role in peptide uptake by gp96.

\section{EXPERIMENTAL PROCEDUES}

Bacterial Strains, Plasmids, and Mutagenesis. Plasmids were propagated in JM109. Single-stranded (ss) DNA for oligo-directed mutagenesis was prepared from plasmidcontaining RZ1032, a dut ung host. Plasmid pHisGP96 expresses the wild-type (WT) form of His-gp96, which is murine gp96 with an $\mathrm{N}$-terminal hexa-His extension. The plasmid is identical to pZ010, which is described in ref 27, except for three restriction site changes made as follows. An EcoRI site in the vector region of pZ010 was removed by restriction with HindIII and NcoI, end-filling with Klenow enzyme, and religation. Oligo-directed mutagenesis of pZ010 ssDNA was used to remove one of two MscI sites within gene 96 and to add a unique NsiI site immediately following the coding region. To make ssDNA for mutagenesis, strain RZ1032 (pZ010) was infected with helper phage VCSM13 (Stratagene, La Jolla, CA) and the DNA was purified by anion-exchange chromatography (Qiagen, Valencia, CA). The mutagenic oligonucleotides used were GACACCAAACTGTCCAATCAGTTCAG, corresponding to bp 4893 to 4918 in pZ010, and CTCCACACGGGATGCATAGCGAGAG-
TA, bp 3044 to 3070 (the mutated base in pZ010 is in italics). The oligos were phosphorylated with T4 polynucleotide kinase. A sample of $40 \mathrm{pmol}$ of oligo was annealed to a 1 $\mu \mathrm{g}$ ssDNA template in $10 \mu \mathrm{L}$ of buffer $(40 \mathrm{mM}$ Tris $\mathrm{HCl}$, $\mathrm{pH}$ 7.5, $20 \mathrm{mM} \mathrm{MgCl} 2,2 \mathrm{mM}$ dithiothreitol). The DNAoligo mixtures were diluted $1: 1$ with extension buffer (2.2 $\mathrm{mM}$ ATP, $100 \mu \mathrm{g}$ of bovine serum albumin $/ \mathrm{mL}, 0.5 \mathrm{mM}$ all four deoxyribonucleoside triphosphates plus 5 units of unmodified T7 DNA polymerase and 200 units of T4 DNA ligase) and incubated for $1 \mathrm{~h}$ at $37^{\circ} \mathrm{C}$. Competent $d u t^{+} u n g^{+}$ cells were transformed with the DNA-oligo mixtures and plated in LB soft agar ( $0.7 \%$ agar) on LB plates (1.8\% agar) containing $100 \mu \mathrm{g}$ of ampicillin $/ \mathrm{mL}$. Candidate plasmids were screened for the loss $(M s c \mathrm{I})$ or gain (NsiI) of a restriction site and sequenced to ensure that they contained no unplanned mutations. DNA fragment exchange was used to assemble the three restriction site changes into pHisGP96. The amino acid sequence of His-gp96 protein encoded by pZ010 and pHisGP96 is identical. The polymerase chain reaction (PCR) was used to construct plasmid pHisGP96/ dimerization domain deletion (DDD), which encodes a mutant His-gp96 with a deletion of its dimerization domain. The reaction $(100 \mu \mathrm{L})$ contained template DNA (pHisGP96, $10 \mathrm{ng}), 100$ pmol each of oligo PCR1 and PCR3, $2.5 \mathrm{mM}$ $\mathrm{MgCl}_{2}, 200 \mu \mathrm{M}$ all four deoxyribonucleoside triphosphates, and $2.5 \mathrm{U}$ of Taq polymerase. Oligo PCR1, ATTCCCTAGTCTTAAGATGCTTCGCCTCAGTTTAAACATTGACCC, has 16 bases of noncomplementary DNA, including an AflII site (italicized) followed by the reverse complement of pZ010 from base 3260 to 3232. Oligo PCR3, AGCAACTGGTCTTAAGGTCTCTGATCAGTGGGTGTCTAGG, has 16 bases of noncomplementary DNA, including an AflII site (italicized) followed by pZ010 bases 3396 to 3419. The reaction consisted of cycles of $1 \mathrm{~min}$ at $94{ }^{\circ} \mathrm{C}, 1$ min at $69{ }^{\circ} \mathrm{C}$, and $3 \mathrm{~min}$ at $72{ }^{\circ} \mathrm{C}$ and ended with $7 \mathrm{~min}$ at $72{ }^{\circ} \mathrm{C}$. The PCR product was gel-purified (Qiagen) and digested with AflII. The resulting $5.5 \mathrm{kbp}$ product was gelpurified, ligated, and used to obtain ampicillin-resistant transformants. Candidate plasmids were screened for the acquisition of a unique $A f l I I$ site and sequenced to ensure they had the precise deletion as well as no unplanned mutations. All oligos were obtained from Operon Technologies (Alameda, CA). DNA restriction and modification enzymes were from New England Biolabs (Beverly, MA). PCR reagents and Taq polymerase were from PE Biosystems.

Protein Purification and Analysis. His-gp96 (MW 94 010) and His-gp96/DDD (MW 89 025) were purified by metal chelate chromatography as previously described (27) and by gel filtration HPLC (see the HPLC of gp96 and gp96Peptide-Pyrene Complexes section) and dialyzed against buffer 1E (20 mM $N$-(2-hydroxyethyl)piperazine- $N N^{\prime}-2$ ethanesulfonic acid (HEPES), $\mathrm{pH} 7.5,300 \mathrm{mM} \mathrm{NaCl}$ ). Details of sodium dodecyl sulfate (SDS) polyacrylamide gel and immunoblot methodology can be found in ref 27 . Antibodies used were anti-KDEL (StressGen, Victoria, Canada), which recognizes C-terminal residues, and horseradish peroxidase-conjugated antimouse (Amersham Pharmacia Biotech, Piscataway, NJ).

Matrix-Assisted Laser Desorption-Time-of-Flight Mass Spectrometry (MALDI-TOF MS). WT or DDD gp96 protein samples were analyzed in a solution of a saturated 4-HCCA matrix. Solvent conditions were optimized to favor protein 
solubility. The details of the sample preparation method were published elsewhere (63). A small aliquot $(0.5 \mu \mathrm{L})$ of a protein-matrix $(3 \mathrm{mg} / \mathrm{mL})$ solution was spotted onto the sample plate using the thin-layer method (33). The spot was then washed for a few seconds with $2-4 \mu \mathrm{L}$ of $0.1 \%$ aqueous trifluoroacetic acid (TFA). All spectra were acquired using a MALDI-TOF MS Voyager-DE STR (PE Biosystem, Foster City, CA), operating in linear, delayed extraction mode. This instrument is equipped with a nitrogen laser delivering pulses of ultraviolet light (wavelength $337 \mathrm{~nm}$ ) at $3 \mathrm{~Hz}$ to the matrix spot. Spectra from 200 individual laser shots were averaged (using a 2 ns data channel width) with software provided by the manufacturer. The spectra were calibrated and further analyzed using the program M-over-Z (http:// www.proteometrics.com and http://prowl.rockefeller.edu).

Preparation of His-gp96-Peptide-Pyrene Complexes. A peptide-pyrene conjugate was prepared as described previously (27). Peptide-pyrene binding to WT and DDD gp96 protein was done in a final volume of $100 \mu \mathrm{L}$ of binding buffer (20 mM HEPES/Na ${ }^{+}$, pH 7.8, $20 \mathrm{mM} \mathrm{NaCl}, 2 \mathrm{mM}$ $\mathrm{MgCl}_{2}, 120 \mathrm{mM} \mathrm{KCl}$ ). A fixed concentration of gp96 (WT or DDD) was mixed with increasing concentrations of peptide-pyrene. The molar ratio of peptide to gp96 was varied from 0.01 to 10 . Binding mixtures were prepared at $25^{\circ} \mathrm{C}$, heated at $50{ }^{\circ} \mathrm{C}$ for $15 \mathrm{~min}$, and left to stand at room temperature for $\sim 3 \mathrm{~h}$. A $10 \mu \mathrm{L}$ portion of the reaction was removed and added to $590 \mu \mathrm{L}$ of binding buffer. The fluorescence intensity of this solution was measured (see below), multiplied by 10 (volume compensation), and corrected for buffer intensity to give the total input peptidepyrene for the reaction $\left(F_{\text {total }}\right)$. The remaining $90 \mu \mathrm{L}$ was loaded on a Sephadex G25 gel filtration column equilibrated with binding buffer, and fractions $(50 \mu \mathrm{L}$ each) were collected by gravity flow. The gp96-peptide-pyrene complexes eluted in fractions 3 and 4 , which were pooled and made up to $600 \mu \mathrm{L}$ in binding buffer. The steady-state fluorescence intensity of the samples was measured and corrected for buffer intensity to give the fluorescence intensity of the bound peptide $\left(F_{\text {bound }}\right)$. Because the free peptide was trapped in the column, we estimated the amount of free peptide by the relation $F_{\text {free }}=F_{\text {total }}-F_{\text {bound. }}$. All steady-state fluorescence spectra were made at $23{ }^{\circ} \mathrm{C}$ and recorded using JOBIN YVON/SPEX fluorolog $3 \tau$ instrument (Instruments SA, Inc., Metuchen, NJ), as was previously described (27). The excitation was at $330 \mathrm{~nm}$, and the emission was measured at $396 \mathrm{~nm}$ with a $5 \mathrm{~nm}$ band-pass set for both monochromators.

Circular Dichroism (CD). The gp96-peptide (without pyrene) complexes were prepared at a molar ratio of 1:1 $(\sim 10$ $\mu \mathrm{M}$ each) in $100 \mu \mathrm{L}$ of $\mathrm{Na}^{+}$phosphate buffer ( $\left.\mathrm{pH} 7.8\right)$ and $100 \mathrm{mM} \mathrm{NaCl}$. The complexes were prepared in the same manner as described above for the binding studies. Binding buffer (see above) was not used because it resulted in exceedingly high dynode voltage in the $\mathrm{CD}$ instrument. The complexes were incubated at $23{ }^{\circ} \mathrm{C}$ for $\sim 3 \mathrm{~h}$ before $\mathrm{CD}$ measurements were taken. Samples were loaded in a $0.2 \mathrm{~cm}$ $\mathrm{CD}$ cell, and the spectra were acquired at $23{ }^{\circ} \mathrm{C}$ using an AVIV 62DS spectrometer interfaced with a PC as described before (34). The instrument was calibrated using a two-point calibration method with ammonium (+)-10-camphorsulfonate (35). Wavelength scans were performed between 192 and $260 \mathrm{~nm}$ at $6 \mathrm{~nm} / \mathrm{min}$. The signal was digitized at $1 \mathrm{~nm}$ intervals and averaged with a 4 s step time constant using AVIV 60DS V4 software. Each final scan was an average of four repeats and is presented after baseline buffer correction. The spectra were not smoothed.

Dynamic Light Scattering. Measurements were carried out in a DynaPro-801 instrument developed by ProteinSolutions. This instrument uses the technique of dynamic light scattering in which a beam of light from an Nd:YAG laser lasing at $883 \mathrm{~nm}$ is directed through the protein sample and the fluctuation in intensity of scattered light by molecules is analyzed using single-photon-counting electronics hardware. The output is the translational diffusion coefficient $\left(D_{\mathrm{T}}\right)$ of the particles in solution: $D_{\mathrm{T}}=\tau / q^{2}$, where $\tau$ is the time scale of the intensity fluctuation for each scattering mode and $q$ is the amplitude of the scattering vector. Under the assumption of Brownian motion and a hard-sphere model for the particle, the diffusion coefficient was converted to the hydrodynamic radius $\left(R_{\mathrm{h}}\right)$ of the particles using the StokesEinstein equation

$$
R_{\mathrm{h}}=k_{\mathrm{B}} T / 6 \pi \eta D_{\mathrm{T}}
$$

where $k_{\mathrm{B}}$ is Boltzmann's constant, $T$ is the absolute temperature, and $\eta$ is the viscosity $\left(1.019 \times 10^{-3} \mathrm{~N} \mathrm{~s} \mathrm{~m}^{-2}\right)$. The estimated molecular weight (MW) is based on the assumption that the protein particles are approximate spheres. The MW was calculated using an algorithm based on the relationship

$$
\mathrm{MW}=\left(1.549 R_{\mathrm{h}}\right)^{2.426}
$$

This algorithm was based on linear calibration curves (log $R_{\mathrm{h}}$ vs $\log \mathrm{MW}$ ) constructed using 18 different proteins. In practice, $R_{\mathrm{h}}$ and the MW were calculated using the software Dynapro V.4, which uses the above equations and discrete autocorrelation coefficients as a series of integers from the scattering history of the sample. The basis for calculation of MW and $R_{\mathrm{h}}$ for gp96 was a polydispersed model. Each of these parameters was obtained as an average of 40 separate scattering events for each sample. The concentration of gp96 proteins was $1 \mathrm{mg} / \mathrm{mL}$ in $25 \mu \mathrm{L}$ of storage buffer (27). A solution of bovine serum albumin $(1 \mathrm{mg} / \mathrm{mL})$ was used as a control and found to be monodispersed with a molecular mass of $68 \mathrm{kDa}$.

Equilibrium Analytical Ultracentrifugation. Sedimentation equilibrium experiments were performed in a Beckman model XL-A analytical ultracentrifuge fitted with an AN60Ti rotor. The samples were run at 8000 or $15000 \mathrm{rpm}$ at $10{ }^{\circ} \mathrm{C}$ for $24 \mathrm{~h}$. The proteins were analyzed simultaneously at three different protein concentrations $(0.25,0.5$, and $1 \mathrm{mg} /$ $\mathrm{mL}$ ) in $100 \mu \mathrm{L}$ of binding buffer. The absorbance was measured at $280 \mathrm{~nm}$ as a function of radial rotation. Samples were considered approaching complete equilibrium when scans separated by $6 \mathrm{~h}$ were identical. The sedimentation equilibrium data were analyzed using homogeneous selfassociation models (36). We assumed that there were at least two species in the protein sample, a monomer with a known mass and a multimer with an unknown mass. To obtain a molecular mass for the multimer, the data were fitted to a two-exponential model (36)

$$
\begin{aligned}
A_{\mathrm{r}}=\exp \left[\ln \left(A_{01}\right)+\right. & \left.H_{1} M_{1}\left(X^{2}-X_{0}^{2}\right)\right]+ \\
& \quad \exp \left[\ln \left(A_{02}\right)+H_{2} M_{2}\left(X^{2}-X_{0}^{2}\right)\right]+E
\end{aligned}
$$


where $A_{\mathrm{r}}$ is the absorbance at radius $X, A_{01}$ is the absorbance of species 1 at reference radius $X_{0}, A_{02}$ is the absorbance of species 2 at the reference radius at $X_{0}, H_{1}$ is the constant (1 $\left.-v_{1} Q\right) \omega^{2} / 2 R T$ for species $1, v_{1}$ is the partial specific volume (0.74), $\omega$ is the angular velocity of the rotor, $Q$ is the density of the solvent in $(\mathrm{mL} / \mathrm{g})^{-1}, H_{2}$ is the constant $\left(1-v_{2} Q\right) \omega^{2} /$ $2 R T, v_{2}$ is the partial specific volume for species $2, M_{1}$ is the molecular weight for species $1, M_{2}$ is the molecular weight for species $2, X_{0}$ is the reference radius, and $E$ is the baseline offset.

The data fit was done using global analysis software provided by Beckman, and the fit was assessed using the random distribution of weighted residuals (not shown), which represent the difference between experimental values and calculated values normalized by the standard deviation and by $\chi$-square analysis $\left(\chi^{2}=\sim 1.5\right)$. The mass determinations were accurate within $\pm 5 \%$.

Scanning Transmission Electron Microscopy (STEM) Analysis. A $3 \mu \mathrm{L}$ sample of WT or DDD gp96 at $1-200$ $\mu \mathrm{g} / \mathrm{mL}$ was injected into a drop of buffer $\left(20 \mathrm{mM} \mathrm{Na}^{+} /\right.$ HEPES, pH 7.9, $300 \mathrm{mM} \mathrm{NaCl})$ on a thin $(2-3 \mathrm{~nm})$ carbon film supported by a thick holey film over a titanium grid. Tobacco mosaic virus (TMV) was applied first as an internal standard. The grid was washed three times with injection buffer, five times with $300 \mathrm{mM}$ ammonium acetate, and then 10 times with $20 \mathrm{mM}$ ammonium acetate; blotted to a thin layer of liquid; plunged into liquid-nitrogen slush; and freezedried (under vacuum) overnight before being transferred to the microscope. The STEM is unique in its ability to visualize individual biological molecules directly without staining, fixing, or shadowing. The microscope is operated in a darkfield mode in which annular detectors collect nearly all of the scattered electrons. A digital image is obtained which consists of $512 \times 512$ pixels, showing the number of scattered electrons from each pixel. The number of scattered electrons in each pixel is directly proportional to the mass thickness in that pixel. In general, mass measurements were made by choosing areas with relatively clean backgrounds and with an adequate number of specimen particles. The background is computed for clean areas and subtracted from the intensity summed over the particles. The microscope calibration factor is checked against the TMV, and the summed intensities (minus the background) multiplied by the calibration factor give the mass values for the specimen. Here, particles of WT gp96 (or DDD) were selected manually (by human eye) and analyzed with the PCMass program 1.4 written by J. S. Wall (Brookhaven National Laboratory). The STEM facility at Brookhaven National Laboratory and its analysis capabilities have been reviewed (37).

Fluorescence Lifetime and Anisotropy Decay. Timeresolved fluorescence experiments were performed by the time-correlated, single-photon-counting method. Samples were excited by short $\left(\sim 2^{\circ}\right.$ ps full width at half-maximum $)$ pulses of vertically polarized laser light. The laser system was a frequency-doubled diode laser (Coherent Verdi V-10), operating at $532 \mathrm{~nm}$, pumping a Ti:sapphire laser (Coherent Mira 900), which was tuned to lase at $730 \mathrm{~nm}$ and modelocked at $76 \mathrm{MHz}$. A pulse picker (Coherent 9200) reduced the laser repetition rate to either 2.4 or $1.2 \mathrm{MHz}$, depending on the average lifetime of the sample. The light was then passed through a frequency doubler (Inrad 5-050) to generate $365 \mathrm{~nm}$ pulses for excitation. The emission first passed through a polarizer oriented at either the magic angle (38) for intensity decays or vertically or horizontally for decays used in anisotropy experiments. Emission at $396 \mathrm{~nm}$ was selected by a monochromator with a band-pass of $10 \mathrm{~nm}$, and photons were detected by a microchannel plate photomultiplier tube (Hamamatsu R2809U-06). The sample chamber, collection optics, and timing electronics have been described previously (39). Decay curves were collected into 2000 channels, with a timing calibration ranging from 40 to $390 \mathrm{ps} / \mathrm{channel}$, depending on the average lifetime of the sample, until 40000 counts were in the peak channel.

The method of analysis for the fluorescence decay data depended on the relationship between the temporal width of the instrument response function (IRF) and the timing calibration of the detection electronics. For those experiments where the IRF was broader than the timing calibration, the data sets were analyzed by a standard reconvolution procedure (40) using nonlinear regression (41). For data collected where the IRF was narrower than the timing calibration (essentially a $\delta$ function for the IRF), analyses were performed in a spreadsheet. In all cases, the fluorescence intensity decay, $I_{\mathrm{M}}(t)$, was fit to a sum of exponentials:

$$
I_{\mathrm{M}}(t)=\sum_{i=1}^{n} \alpha_{i} \mathrm{e}^{-t / \tau_{i}}
$$

where $\alpha_{i}$ and $\tau_{i}$ are the amplitude and lifetime of the $i$ th component, respectively, and the subscript $\mathrm{M}$ denotes that the data were obtained through the emission polarizer oriented at the magic angle. For time-resolved fluorescence anisotropy experiments, the $I_{\mathrm{M}}(t)$ decay and the decays collected with the emission polarizer oriented horizontally, $I_{\mathrm{H}}(t)$, and vertically, $I_{\mathrm{V}}(t)$, were fit simultaneously by the following expressions:

$$
\begin{gathered}
I_{\mathrm{H}}(t)=\frac{1}{3} I_{\mathrm{M}}(t)\{1-r(t)\} \\
I_{\mathrm{V}}(t)=\frac{1}{3} I_{\mathrm{M}}(t)\{1+2 r(t)\}
\end{gathered}
$$

The anisotropy function, $r(t)$, is defined by a sum of $m$ exponentials with rotational correlation times, $\phi_{j}$, and preexponential factors, $\beta_{j}(38)$.

$$
r(t)=\sum_{j=1}^{m} \beta_{j} \mathrm{e}^{-t / \phi_{j}}
$$

All fits were judged by the reduced $\chi^{2}$ and the weighted residuals; those fits performed by reconvolution were also examined by the autocorrelation of the residuals.

HPLC of gp96 and gp96-Peptide-Pyrene Complexes. HPLC gel filtration was used to purify gp96 and to separate gp96-peptide-pyrene complexes that were made for fluorescence intensity and anisotropy studies. gp96 or complexes containing a 1:1 molar ratio of gp96 to peptide-pyrene (final concentrations of $3 \mu \mathrm{M}$ ) were injected into a Hydropore-5SEC (Rainin Instruments; $4.6 \mathrm{~mm}$ i.d. $\times 25 \mathrm{~cm}$ length) sizeexclusion column that was attached to a guard column. The elution (isocratic, $0.5 \mathrm{~mL} / \mathrm{min}$ ) was carried out with buffer 1E. Fractions of a volume of $1 \mathrm{~mL}$ were collected during a 20 min period. Under the HPLC conditions used here, free 


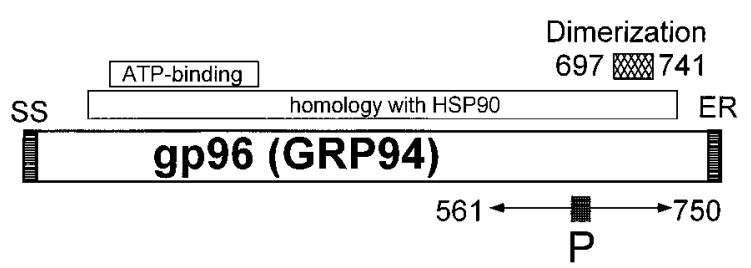

FIGURE 1: Organization of the gp96 protein. gp96 is shown in linear representation, $\mathrm{N}$ to $\mathrm{C}$ terminus, with numbering based on unprocessed murine gp96. The dimerization domain residues 697741 are identical to residues $676-719$ of canine GRP94 (32). The region homologous to HSP90 is indicated with a presumed ATP binding domain. Abbreviations: SS, signal sequence; ER, endoplasmic reticule retention/retrieval signal; $\mathrm{P}$, minimal peptidebinding site. Residues 561-750 have been modeled (29).

peptide-pyrene was not eluted within the run time and had a retention time $>20 \mathrm{~min}$. In the case of complexes, the fractions were analyzed individually for fluorescence emission at $396 \mathrm{~nm}$ by excitation at $330 \mathrm{~nm}$; buffer values were subtracted.

\section{RESULTS}

Rationale and Approach. Figure 1 shows a linear representation of the gp96 protein. The protein has a signal sequence (SS) located at the $\mathrm{N}$ terminus and an ER retention/ retrieval signal at the $\mathrm{C}$ terminus. There is extensive homology with the cytosolic counterpart of gp96, HSP90 (42). The N-terminal region is homologous to the ATPbinding domain of HSP90 (43). The peptide-binding site $\mathrm{P}$ is located in the C-terminal region (29). Wearsch and Nicchitta have shown that residues 697-741 in gp96 form an independent oligomerization domain (residues 676-719 in ref 32). Because the peptide-binding and oligomerization domains are quite close in the linear sequence (Figure 1), they could influence the function of each other in unknown ways (29). We have modeled the peptide-binding pocket of gp96, residues 561-750 (29), on the basis of blockwise amino acid homology with the peptide-binding residues in the crystallographic structure of the MHC class I moleculepeptide complex (44). There is no crystallographic or NMRderived structure for gp96 or its fragments. In our model, the peptide lies in a groove surrounded by $\alpha$ helices and the floor of the peptide-binding pocket is formed by antiparallel $\beta$ sheets. Notably, the dimerization domain abuts the peptidebinding domain in this three-dimensional model. Thus, besides the linear relationship indicated in Figure 1, there is also the possibility of a close physical proximity of the two domains. To explore the potential influence of the dimerization domain on peptide binding, we have constructed a gp96 mutant, the DDD mutant, which lacks amino acid residues 697-741 (Figure 1), and studied its quaternary structure and its peptide-binding properties.

Properties of the DDD Mutant. The WT and mutant (DDD) gp96 proteins were expressed with N-terminal hexaHis tags and were purified from Escherichia coli, using affinity chromatography and HPLC gel filtration (see the experimental procedures). Immunoblot analysis showed that the WT and DDD gp96 proteins migrated as single bands (Figure 2A). The DDD mutant protein migrated slightly faster than the WT band, consistent with removal of the $\sim 5 \mathrm{kDa}$ dimerization sequence (Figure 2A).

Mass spectrometry was used to ascertain the masses and mass difference between WT and DDD gp96 (data not shown). MALDI-MS showed that the measured masses (error $= \pm 0.15 \%$ ) of WT and DDD proteins corresponded to the expected masses on the basis of the primary sequence. The difference in mass between WT and DDD was determined to be $4962 \pm 100 \mathrm{Da}$, in good agreement with the expected mass difference of $4986 \mathrm{Da}$. In summary, both the WT and DDD mutant proteins were intact and were $>95 \%$ pure.

A number of physicochemical techniques were used to investigate molecular self-association of WT gp96 and DDD mutant proteins. The results of gel filtration HPLC established that both the WT and DDD mutant proteins formed aggregates (Figure 2B), although the WT aggregates were clearly larger, on the basis of their shorter retention time and elution at or near the void volume of the column. The aggregates are homooligomeric because SDS gel electrophoresis showed that the samples contained only WT or DDD gp96. Equilibrium analytical ultracentrifugation was used to further characterize the aggregates (Figure 2C). The mean molecular weight of the WT aggregate was $\sim 840 \mathrm{kDa}$, whereas for DDD mutant protein, it was $\sim 557 \mathrm{kDa}$; these values were comparable to the estimates from gel filtration (Figure 2B). These data indicated that there may be eight monomer subunits in a WT aggregate and, for the DDD mutant, there may be 6 . Dynamic light scattering was used to get relative upper limit estimates for $R_{\mathrm{h}}$ and mean MW of aggregates (Figure 2D). For WT aggregates, $R_{\mathrm{h}}$ was 35.6 $\mathrm{nm}$, whereas for the DDD mutant, it was $26.2 \mathrm{~nm}$. WT protein had a mean aggregate MW of $16818 \mathrm{kDa}$, whereas it was $8553 \mathrm{kDa}$ for the DDD mutant (Figure 2D). The masses obtained from light scattering were significantly larger than those obtained using HPLC and ultracentrifugation data. The most likely explanation is that because very large aggregates scatter light better than the smaller ones the light-scattering data was biased to report particles having the larger masses. However, the HPLC and ultracentrifugation data are not inconsistent with the existence of some very large aggregates in the samples (Figure 2B,C). In summary, these techniques established that both WT and, interestingly, the DDD mutant protein formed higher order self-associated complexes. Moreover, all of the techniques used pointed to a shape and/or mass difference between WT and DDD complexes.

For comparison, we tested the aggregation properties of native mouse gp96 isolated from animal tissue (a gift of Dr. Srivastava's laboratory at the University of Connecticut). The protein was isolated using detergent-free methods (61). HPLC gel filtration under conditions identical with those of the recombinant WT gp96 (see the methods) showed that the native mouse protein eluted as a major peak at 4.8 min and two minor peaks at 5.5 and $7.0 \mathrm{~min}$. These retention times are similar to those observed for the recombinant protein (Figure 2B). We also used dynamic light scattering to assess the aggregation of native mouse gp96. The mean MW was $16569 \mathrm{kDa}$, and the mean $R_{\mathrm{h}}$ was $43.3 \mathrm{~nm}$. These values are also in agreement with those reported for the recombinant gp96 (Figure 2D). These studies indicate that the multimeric aggregation properties of the recombinant gp96 are shared by the native mouse gp96 protein and thus establish that the predominant forms of gp96 are higher order aggregates.

STEM Analysis of gp96. To study the higher order structures in detail, we used the STEM. The STEM records 
A

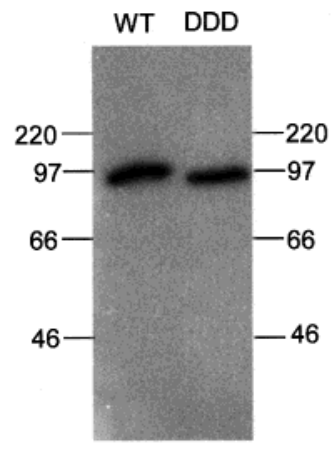

B

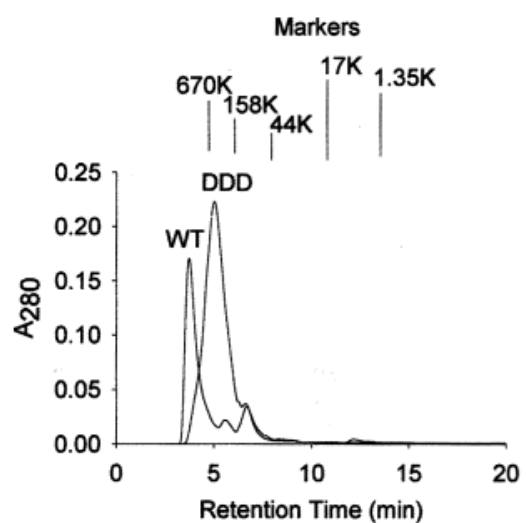

$\mathrm{C}$

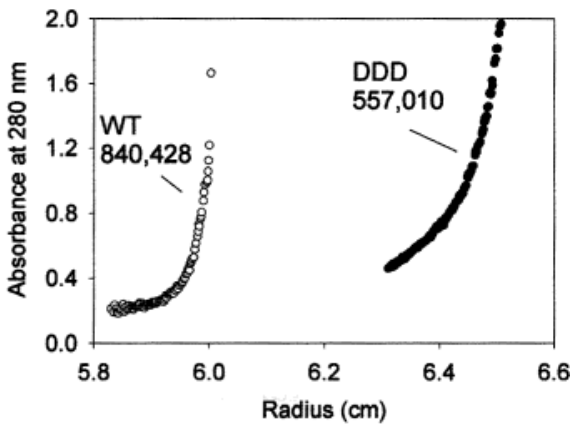

$\mathrm{D}$
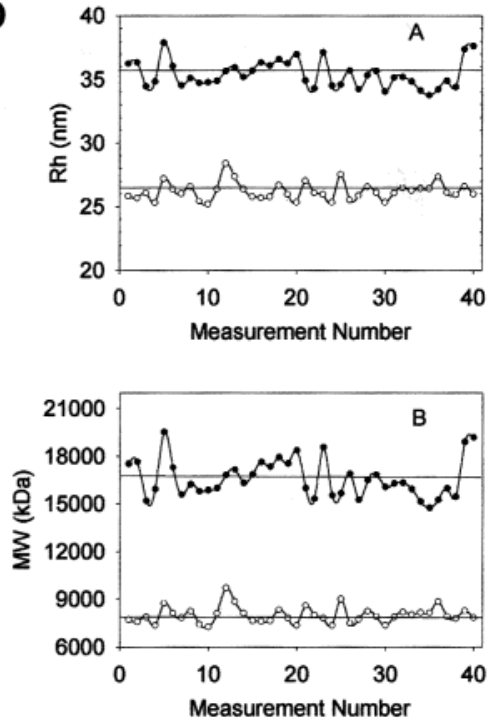

FIGURE 2: Characterization of purified WT gp96 and DDD mutant proteins. (A) Immunoblot of a 10\% acrylamide-SDS gel probed with C-terminus-recognizing antibody (anti-KDEL) and developed with horseradish peroxidase conjugated secondary antibody. Gel lanes contained $1 \mu \mathrm{g}$ of protein heated in $2 \%$ SDS. The protein markers (in $\mathrm{kDa}$ ) are as follows: $220 \mathrm{kDa}$, myosin; $97 \mathrm{kDa}$, phosphorylase b; $66 \mathrm{kDa}$, bovine serum albumin; $46 \mathrm{kDa}$, ovalbumin. Probing with N-terminal specific antibodies gave the same result (not shown). (B) HPLC gel filtration chromatography of WT and DDD proteins. The positions of mass standards (Bio-Rad) used for calibration are indicated at the top of the chromatogram. Masses: $670 \mathrm{kDa}$, thyroglobin; $158 \mathrm{kDa}$, IgG; $44 \mathrm{kDa}$, ovalbumin; $17 \mathrm{kDa}$, myoglobin; $1.35 \mathrm{kDa}$, vitamin B-12. (C) Representative sedimentation equilibrium data. The $x$ axis shows the radial position of the boundary of the protein sample in the cell after attaining the desired rotor speed $(8000 \mathrm{rpm})$, and the $y$ axis gives the absorbance of the protein. The average molecular mass of the aggregates is indicated (see the methods). (D) Dynamic light scattering. Parameters obtained from 40 individual light-scattering measurements are presented. Panel A shows $R_{\mathrm{h}}$, whereas panel B shows the mass (MW) of the aggregates. Symbols used: filled circles, WT gp96; open circles, DDD mutant gp96. The mean values are shown as straight lines. The same concentration of protein was used for both WT and mutant gp96 (1 mg/mL in storage buffer (27)).

images of individual molecules or particles without staining, fixing, or shadowing, permitting the visualization of structures approximating the native states (Figure 3). Both WT and DDD mutant proteins yielded complexes of various sizes ranging from individual molecules to massive particle clusters (Figure 3A), suggesting many different states of aggregation. The masses of more than 300 individual particles or clusters of particles were determined for both the WT and DDD mutant proteins. Figure 3B shows histograms of particle masses normalized to the mass of a single gp96 subunit $(94.010 \mathrm{kDa}$, WT gp96; $89.025 \mathrm{kDa}$, DDD mutant). The majority of particles $(87-88 \%)$ contained 24 or fewer subunits. The remaining particles had unique masses ranging up to $25 \mathrm{MDa}$ or $\sim 200-250$ subunits (not shown). For WT gp96, dimers were only slightly more frequent than other forms, and for the DDD mutant protein, monomers through tetramers were about equally represented. There was no bias for particles of either species to contain either an even or an odd number of subunits. Enlarged views of particles were analyzed to gain insight into the architecture of gp96 aggregates (Figure 3A). Large, very large, or massive particles appeared to consist of clusters of smaller particles, and the sizes and masses of these appeared similar to those of isolated dimers or tetramers. A few of the large particles were made up of smaller particles arranged in a complete or partial ring or rings linked together (e.g., see Figure 3A, WT, 24 subunits). Large particles of the DDD mutant protein appeared more compact, and fewer rings were seen. The smaller particles were studied closely (Figure 3A, boxes) and measured to obtain their average dimensions (Figure 3C, table). Monomeric units were slightly elongated, averaging $7.6 \times 5.5 \mathrm{~nm}$ (length $\times$ width), and some views suggested that there were perhaps two domains. Many of the larger particles, including DDD particles, also appeared slightly longer in one dimension. Thus, particles increased in both length and width as subunit numbers increased; chains were not observed. The detailed appearance of most particles was probably affected by how they adsorbed to the grid. Some dimers appeared globular, whereas others had two domains. Trimers consisted of three domains arranged either linearly 

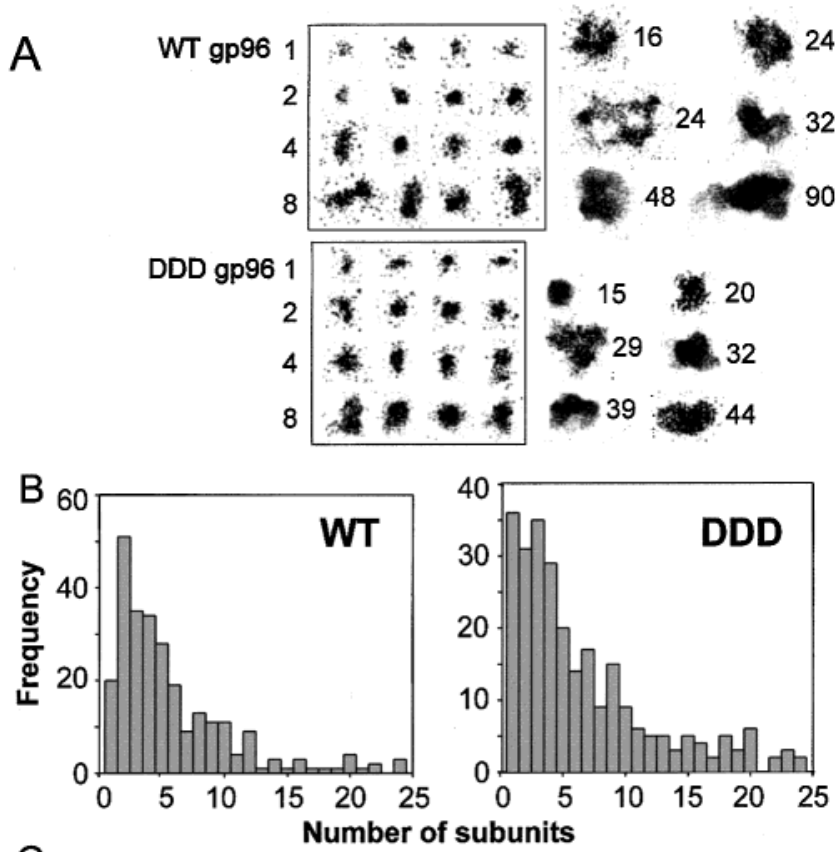

C

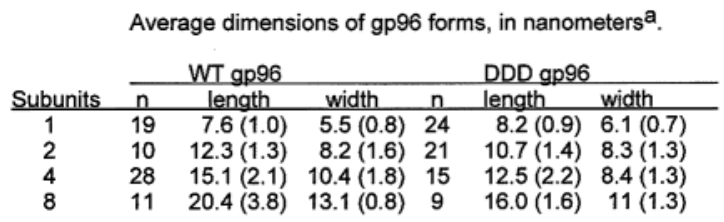

a Images of unstained gp96 were recorded digitally and analyzed after manual selection. Areas with clean background and well-spaced particles were studied. Images were enlarged using Adobe Photoshop. A conversion factor of $1 \mathrm{~nm} /$ pixel was applied. $\mathrm{n}=$ number of particles measured.

FIGURE 3: STEM images of WT and DDD mutant gp96. (A) Representative images of WT and DDD mutant particles ranging from monomer units to large particle aggregates are shown. (B) The subunit distribution of WT and DDD aggregates having 1-24 subunits. The masses of 300 particles each of WT and DDD gp96 were determined, and the number of subunits in each particle was calculated. The histograms show, for those having 1-24 subunits ( $87-88 \%$ of the total), the number of particles counted (ordinates) versus the specified number of subunits per particle (abscissas). (C) The average length and width of individual monomer to octamer species is given in nanometers. The numbers in parentheses are the standard deviations.

or triangularly, or they had two domains (not shown). Tetramers were globular or had two domains. Octamers had one or two domains, etc. Our ability to assign a mass to each of the particles proved crucial to their identification. In general, WT gp96 particles were slightly larger than DDD mutant particles having an identical number of subunits, suggesting that particles of the latter variety were more compact (Figure 3A,C). We do not list the dimensions of the larger particles here because, for a given number of subunits, there were so few examples, and when there was more than one example, they often differed greatly in shape probably because of their different arrangements of subunits or orientations on the grids.

Peptide-Binding Properties of WT and DDD Proteins. We have previously developed a fluorescence-based quantitative assay for peptide binding to gp96 (27). In this assay, a pyrene-labeled peptide ligand (Figure 4) was allowed to bind gp96 and the binding was quantitated by studying the spectral properties of the pyrene (45-49). Peptide-pyrene shows the characteristic emission of pyrene, a major band centered at

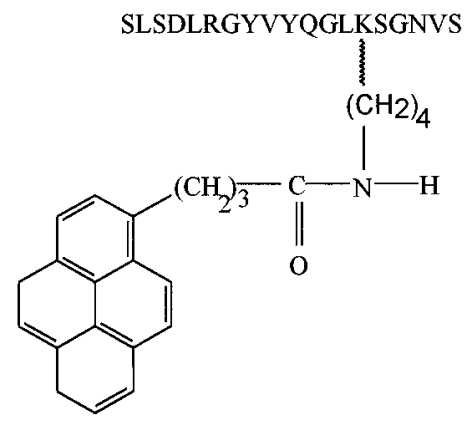

FIGURE 4: Structure of the peptide-pyrene conjugate. An immunogenic peptide derived from the nucleocapsid of vesicular stomatitis virus (13) and known to be chaperoned by gp96 $(13,15$, $17,25)$ was covalently labeled with pyrene at the unique Lys $(\mathrm{K})$ position as described in ref $27 .\left(\mathrm{CH}_{2}\right)_{4}$ and $\mathrm{NH}$ are from the $\epsilon$-amino group of the Lys side chain. The $\mathrm{C}_{\alpha}$ linkage to the side chain in $\mathrm{K}$ is shown schematically with a squiggly line. The four-ringed pyrene serves as a fluorescent reporter molecule for studying the interaction of the labeled peptide with gp96.
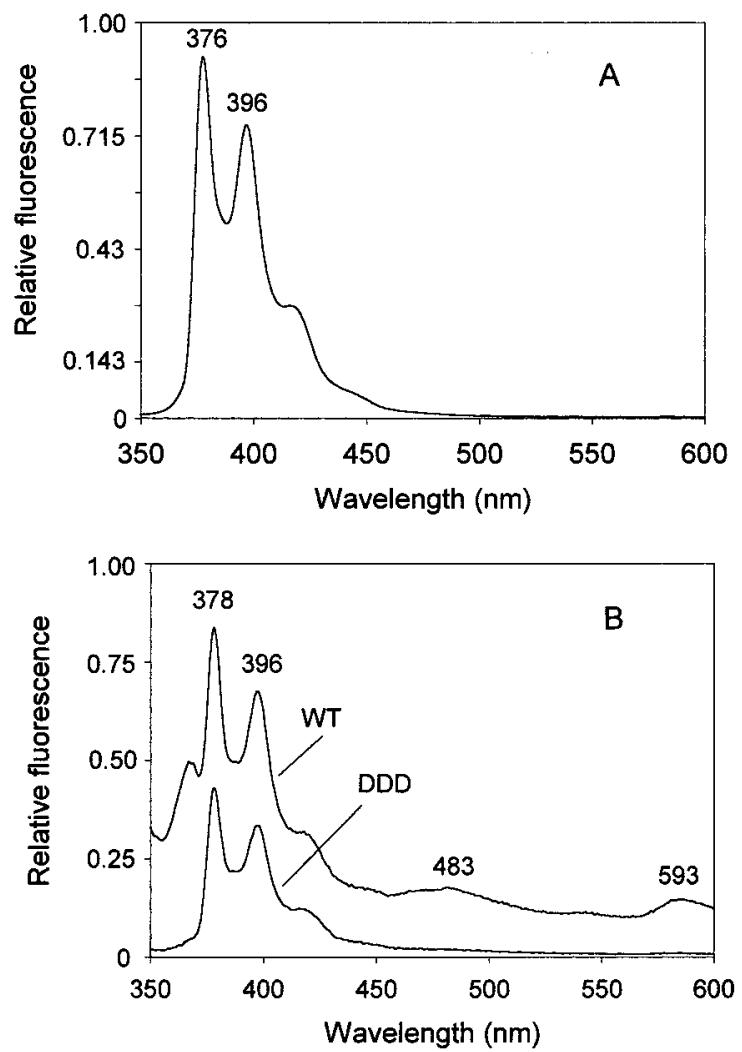

FIGURE 5: (A) Emission spectrum of peptide-pyrene (excitation at $330 \mathrm{~nm}$ ). (B) Emission spectra of peptide-pyrene when bound to WT gp96 or DDD mutant protein (excitation was at $330 \mathrm{~nm}$ ). The emission peaks at 378 and $396 \mathrm{~nm}$ are from peptide-pyrene in monomer complexes (27). The emission bands centered at 483 and $593 \mathrm{~nm}$ are from pyrene excimers in gp96 dimer complexes (27). The excimer bands are absent from the emission spectrum of the DDD mutant protein-peptide complexes, as was the shoulder at $368 \mathrm{~nm}$. The scans shown in B were obtained from WT and DDD samples containing the same protein concentration and were plotted to the same scale.

$376 \mathrm{~nm}$ and a less intense band centered at $396 \mathrm{~nm}$ (Figure 5A).

Peptide-pyrene-gp96 complexes were formed under equilibrium binding conditions and were separated from free peptide - pyrene by gel filtration through Sephadex G-25. The fluorescence of the complexes, which eluted in the void 
A
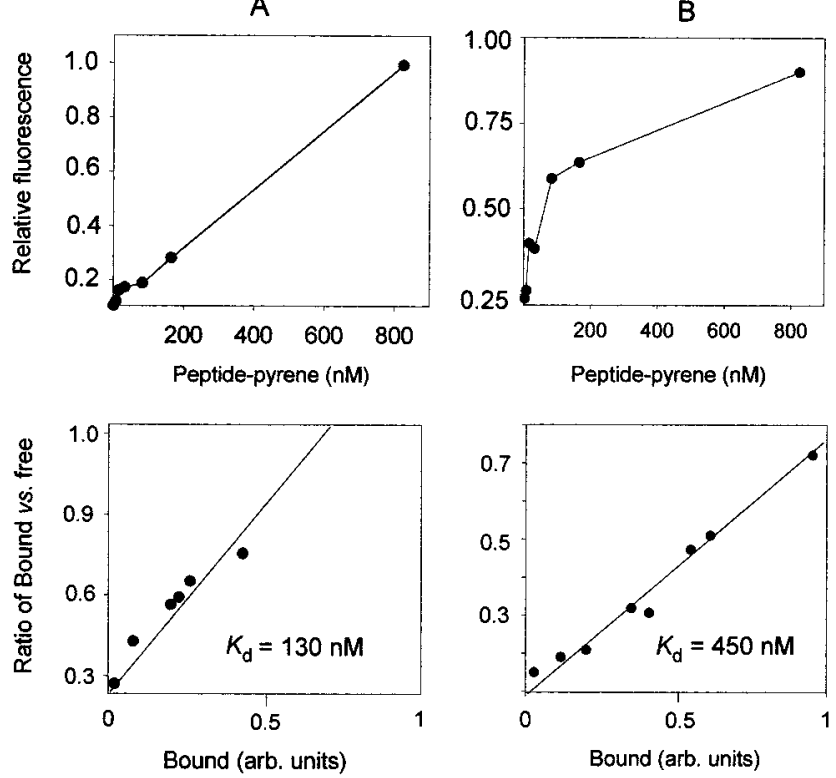

Figure 6: Binding of peptide-pyrene to WT (A) and DDD (B) gp96. Upper panels show typical binding isotherms. The fluorescence of the bound peptide-pyrene in complexes (ordinates) is plotted against the initial concentration of peptide-pyrene $(a b-$ scissa). The complexes were first eluted from a mini gel filtration column (see the experimental procedures), and the fluorescence was measured by excitation at $330 \mathrm{~nm}$. Each point in the graph represents an average from three independent experiments. The gp96 protein was at $100 \mathrm{nM}$. Lower panels show modified Scatchard plots. The free or bound indicates the fluorescence from either free or gp96-bound peptide-pyrene, which is expressed in arbitrary units. Column A presents data for WT gp96, whereas column B shows data for the DDD mutant protein. The $K_{\mathrm{d}}$ values were derived from the slopes of the binding curves in the lower panels.

volume, was measured. The intensity of the pyrene monomer emission at 378 and $396 \mathrm{~nm}$ suggested that fluorescence from the WT gp96-peptide complexes was about 3-fold greater than that of the DDD gp96-peptide complexes (Figure 5B). Furthermore, the excimer (pyrene dimer) bands centered at 483 and $583 \mathrm{~nm}$ in the WT complexes were absent in the DDD complexes (Figure 5B). These results are in agreement with our previous findings that WT gp96-peptide complexes may exist as dimers with each monomer bound to a peptide $(27,29)$.

Increasing concentrations of peptide-pyrene were used to titrate a fixed concentration of gp96 under equilibrium binding conditions. The fluorescence intensity at $396 \mathrm{~nm}$ was plotted against the concentration of peptide-pyrene (Figure 6). On the basis of the relative qualitative shapes of the binding isotherms over the same range of peptide concentration, WT gp96 binds the peptide somewhat better than the DDD mutant. At low substrate concentrations (upper panels), the shape of the binding curve for WT gp96 was linear (Figure 6A), but for the DDD mutant protein, it was somewhat convex (Figure 6B). The shape of the DDD binding curve suggests that the DDD mutant protein was closer to saturation binding than WT gp96 at lower ligand concentration. A comparison of the $K_{\mathrm{d}}$ values from the modified Scatchard plots in Figure 6 (lower panels) suggests that the strength of peptide binding is somewhat, but not dramatically, affected by the deletion of the dimerization domain. These findings are consistent with our model (29), which places the dimerization domain very close to, but not within, the peptide-loading site.
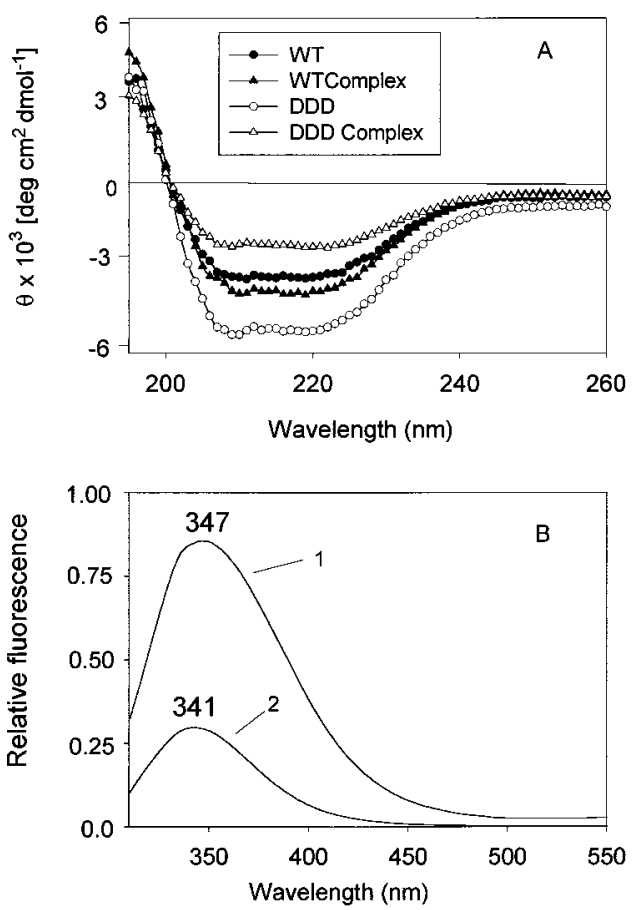

FIGURE 7: (A) CD spectrum of free and peptide-bound WT gp96 or DDD mutant protein. The concentration of WT or DDD gp96 was $10 \mu \mathrm{M}$ in all samples; where used, the peptide concentration was $10 \mu \mathrm{M}$. In these experiments, $>95 \%$ of the gp96 protein was bound by the peptide. The CD spectra were normalized according to the method in ref 60. (B) Intrinsic Trp fluorescence of WT and DDD mutant proteins. Excitation was at $295 \mathrm{~nm}$. The samples contained $2 \mu \mathrm{M}$ WT gp96 (curve 1) or DDD mutant protein (curve 2 ) in binding buffer (see the experimental procedures). The emission maxima are indicated.

Structural Changes in Complexes. To examine any structural changes upon peptide binding by WT and DDD mutant gp96, we monitored the protein secondary structure using $\mathrm{CD}$ spectroscopy. There was little or no change in the CD spectrum when the peptide was bound to WT gp96 (Figure 7A). However, the DDD mutant protein underwent a dramatic change in conformation upon binding the peptide (Figure 7A). Specifically, there was a decrease in $\alpha$ helicity. The uncomplexed DDD mutant protein appeared to have increased $\alpha$ helicity compared to that of WT gp96, even though it has a deletion of 45 amino acids. The predicted $\alpha$ helicity based on probability calculations using the primary sequence is approximately the same (38\%) for WT gp96 and the DDD mutant protein (not shown). The result suggests that some segment(s) of the DDD mutant protein switched conformation to an $\alpha$ helix. The conformational change appears to be reversed by peptide binding. Because both WT and DDD show aggregates of similar mass distribution (Figure 3) and because the protein-peptide concentrations were the same in both cases, protein aggregation per se cannot be the cause of relative CD alterations. Collectively, our results suggest that the dimerization domain not only plays a role in peptide binding but also is involved in maintaining the secondary structure of gp96. We suggest that this could indicate an interplay of the domains of gp96.

To probe the gp96 structure further, we examined the tertiary structure using intrinsic Trp fluorescence. The Trp fluorescence intensity of the DDD mutant (curve 2, Figure 7B) was 3-4-fold lower compared to that of the WT protein (curve 1) using the same concentration of protein. This is 
Table 1: Fluorescence Intensity Decay Parameters

\begin{tabular}{|c|c|c|c|c|c|c|c|c|c|c|c|c|c|c|c|}
\hline sample $^{a}$ & $\alpha_{1}^{b}$ & $\alpha_{2}$ & $\alpha_{3}$ & $\alpha_{4}$ & $\begin{array}{c}\tau_{1} \\
(\mathrm{~ns})\end{array}$ & $\begin{array}{c}\tau_{2} \\
(\mathrm{~ns}) \\
\end{array}$ & $\begin{array}{c}\tau_{3} \\
(\mathrm{~ns}) \\
\end{array}$ & $\begin{array}{c}\tau_{4} \\
(\mathrm{~ns})\end{array}$ & $\% \alpha_{1} \tau_{1}^{c}$ & $\% \alpha_{2} \tau_{2}$ & $\% \alpha_{3} \tau_{3}$ & $\% \alpha_{4} \tau_{4}$ & $\begin{array}{c}\tau^{-} \\
(\mathrm{ns})^{d}\end{array}$ & $\begin{array}{c}\langle t\rangle \\
(\mathrm{ns})^{e}\end{array}$ & $\chi^{2 f}$ \\
\hline PP/buf & 0.11 & 0.89 & & & 9.5 & 32 & & & 3.5 & 96.5 & & & 30 & 31 & 1.14 \\
\hline PP/gly & 0.18 & 0.07 & 0.75 & & 9.3 & 50 & 162 & & 1.3 & 3.0 & 95.7 & & 127 & 157 & 1.65 \\
\hline $\mathrm{PP}+\mathrm{WT}^{g}$ & 0.15 & 0.23 & 0.52 & 0.10 & 2.0 & 12 & 94 & 205 & 0.4 & 3.7 & 67.6 & 28.3 & 72 & 123 & 0.99 \\
\hline $\mathrm{PP}+\mathrm{DDD}^{g}$ & 0.16 & 0.19 & 0.60 & 0.05 & 2.1 & 13 & 93 & 201 & 0.4 & 3.5 & 81.4 & 14.7 & 69 & 107 & 1.11 \\
\hline
\end{tabular}

${ }^{a}$ Abbreviations: PP, pyrene-labeled peptide; buf, buffer; gly, glycerol; WT, wild-type gp96; DDD, mutant gp96. ${ }^{b}$ Amplitudes normalized to a sum of $1 .{ }^{c}$ The percent contribution of each exponential component to the total fluorescence intensity: $100 \alpha_{i} \tau_{i} / \sum \alpha_{i} \tau_{i}{ }^{d}$ The number-average lifetime: $\sum \alpha_{i} \tau_{i} / \sum \alpha_{i} .{ }^{e}$ The intensity-weighted lifetime: $\sum \alpha_{i} \tau_{i}{ }^{2} / \sum \alpha_{i} \tau_{i}{ }^{f} \mathrm{~A}$ measure of the goodness of fit. ${ }^{g}$ Averaged from the three experiments listed in Table 2, with the complexes in buffer.

not due to loss of Trp residues: the total number of Trp residues is the same in DDD as in WT gp96. In addition, the emission maximum of the DDD mutant protein is $\sim 5$ $\mathrm{nm}$ below that measured for WT gp96. This blue shift, along with the decreased overall Trp fluorescence quantum yield of the DDD mutant, suggests that one or more Trp residues are buried more completely into the DDD protein matrix. Thus, the tertiary structure of the DDD protein may be more compact than that of the WT. This is consistent with the finding that DDD gp96 appears more compact in the STEM.

Time-Resolved Fluorescence Spectroscopy. On the basis of our model of the peptide-binding pocket (29), deletion of the dimerization domain should alter its shape and/or size, which may affect the environment of bound peptide. We showed earlier that the pyrene fluorescence lifetime could be used as a sensitive indicator of changes in the peptidebinding environment of gp96 (27). Accordingly, we examined the interaction between gp96 and the peptide through the use of time-resolved fluorescence. With this technique, kinetic parameters that describe the rate of loss of the excited state (intensity decay) and the rate of change in the polarization of the excited state (anisotropy decay) help to describe the molecular interactions that a fluorophore experiences and the local environment of the fluorophore. Timeresolved fluorescence experiments were carried out using a time-correlated, single-photon counting instrument (ref 39; see the methods).

The fluorescence intensity decay of peptide-pyrene was found to be essentially a single exponential, with $96 \%$ of the fluorescence from a $32 \mathrm{~ns}$ component (Table 1). To examine the effect of a different solvent environment on the fluorescence properties of the pyrene probe, and thus to help explain results obtained for the peptide bound to gp96, the peptide was also placed in glycerol. (Glycerol was chosen because of the anisotropy studies; see below.) The intensity decay of the pyrene-labeled peptide in $90 \%$ glycerol (by volume) is increased substantially to $162 \mathrm{~ns}$ (Table 1). Again, the decay is dominated by one component but with a considerably longer lifetime. Possible factors contributing to the increased lifetime in glycerol include a decreased amount of collisional quenching arising from the increased viscosity and overall solvent effects on the excited state of pyrene. In both solvents, the cause of the extra exponential terms remains to be resolved. However, because the peptide will exist as a random coil in these solutions, one or more configurations could yield different local environments for the pyrene probe, resulting in a different quantum yield and lifetime for each configuration.

When peptide - pyrene was bound to either WT or DDD gp96, the mean lifetimes increased dramatically (from $\langle\tau\rangle$

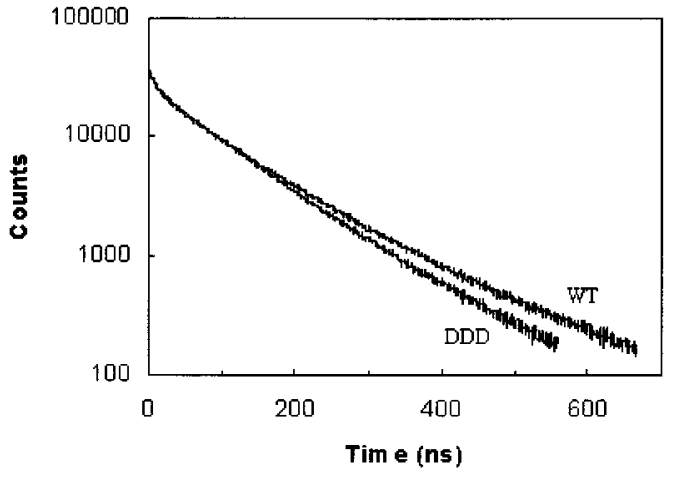

FIGURE 8: Fluorescence intensity decay curves revealing the difference between the peptide-pyrene complexes with WT and DDD gp96. The concentration of the protein was $3 \mu \mathrm{M}$. Greater than $85-90 \%$ of gp96 in the gp96-peptide-pyrene complexes was bound by the peptide.

$=31$ to $>100 \mathrm{~ns}$; Table 1), indicating that pyrene (and probably the peptide) was now in a more hydrophobic environment. This interpretation is also consistent with the observed increase in lifetime seen in $90 \%$ glycerol. The increase in the mean lifetime for the pyrene probe upon binding is consistent with the known complex of the peptide with the WT or DDD mutant gp96. The fluorescence intensity decay of the WT gp96-peptide complex with the pyrene-labeled peptide was multiexponential, requiring four lifetimes, with most of the fluorescence arising from the two longer components (Table 1). Two important points about the intensity decay of the DDD mutant gp96-peptide complex should be noted. First, it has the same four lifetimes as the WT complex (Table 1). Second, there is a shorter decay profile for the DDD mutant-peptide complex, as is demonstrated in Figure 8, stemming from a difference in the magnitude of the amplitude terms for the two longer lifetimes. The ability to describe the decay of both complexes with the same lifetimes supports the idea that the multipleexponential components could be a result of multiple environments for the pyrene probe that are equivalent. If this is the case, then the difference(s) between the decay kinetics of the peptide-pyrene probe in the WT and DDD complexes reflects a redistribution of conformational states in the binding site. The ability to have multiple states implies that the pyrene on the $\epsilon$-amino group of the peptide's Lys side chain (Figure 4) has both the mobility and the space to move around within the binding site.

Fluorescence anisotropy provides information about the size and shape of a macromolecule in solution. In addition, time-resolved fluorescence anisotropy, $r(t)$, relates the dynamic motions of a fluorophore and, therefore, yields information about its environment (50). We carried out $r(t)$ 


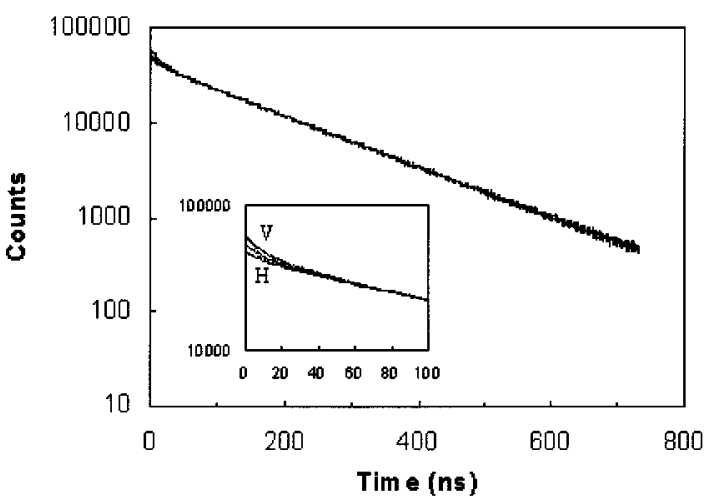

FIGURE 9: Fluorescence decay curves obtained to determine the fluorescence anisotropy decay of the pyrene-labeled peptide dissolved in $90 \%$ glycerol. The inset demonstrates that the curves differ only at early times. The top curve $(\mathrm{V})$ in the inset is the $I_{\mathrm{V}}(t)$ decay, and the bottom curve $(\mathrm{H})$ is the $I_{\mathrm{H}}(t)$ decay (see the methods). The unlabeled middle curve is $I_{\mathrm{M}}(t)$, the intensity decay in the absence of polarization effects.

studies to investigate whether the mobility of the pyrene probe is affected when the labeled peptide is bound to WT or DDD mutant gp96. We are unable to detect any $r(t)$ for peptide-pyrene in buffer: the depolarization occurred too fast for us to measure it (data not shown). Under our experimental conditions, a lower limit for the recovery of a rotational correlation time is $1-2 \mathrm{~ns}$. However, the rotational correlation time for the depolarization of a pyrene ring system linked to a Lys side chain can be estimated to be 1 order of magnitude shorter. Therefore, to measure an $r(t)$ for the peptide, we examined it in $90 \%$ glycerol (Figure 9); the glycerol slows motions substantially because of the $>100$ fold increase in viscosity. As can be seen in the inset of Figure 9, a difference can be observed only at early times between the decays collected through orthogonal angles of an emission polarizer. In contrast, for the peptide in buffer, the curves were superimposable over the whole time range (data not shown). Surprisingly, no $r(t)$ for the peptide-pyrene in either the WT or the DDD mutant gp96 complex was observed: that is, the decays were again superimposable over the whole time range (data not shown). This implies that depolarization occurs faster than can be resolved, as was found for peptide-pyrene in buffer. For this rapid depolarization to happen within the complex, the pyrene probe and its Lys side-chain linkage must have considerable free space within the peptide-binding pocket to permit rapid motions. This result could also suggest that even a significant portion of the peptide may have considerable room in the binding site.

In summary, these time-resolved fluorescence studies suggest the following. First, to allow multiple states to exist and to enable rapid depolarization, the gp96 peptide-binding pocket must provide considerable free space for the Lys side chain in the middle of the test peptide. In fact, this space is sufficient such that introduction of the pyrene probe does not invoke steric interactions. Second, removal of the dimerization domain of the gp96 protein affects the peptidebinding site. Although the pyrene probe reports that the actual local environments appear to be similar in both the WT and DDD mutant peptide-binding domains, the thermodynamics of the complexes are different, leading to different populations of the various species.
Table 2: Comparative Fluorescence Intensity Decay Parameters for WT and DDD Complexes

\begin{tabular}{|c|c|c|c|c|c|c|c|c|}
\hline sample & description $^{a}$ & $\begin{array}{c}\delta \\
\text { days }\end{array}$ & $\alpha_{i}^{b}$ & $\begin{array}{c}\tau \\
(\mathrm{ns})\end{array}$ & $\% \alpha \tau^{c}$ & $\begin{array}{l}\tau^{-d} \\
(\mathrm{~ns})\end{array}$ & $\begin{array}{l}\langle\tau\rangle^{e} \\
\text { (ns) }\end{array}$ & $\chi^{2 f}$ \\
\hline \multirow[t]{12}{*}{1} & \multirow[t]{12}{*}{ Pep + WT } & \multirow[t]{4}{*}{1} & 0.22 & 1.8 & 0.6 & \multirow[t]{4}{*}{65} & \multirow[t]{4}{*}{119} & \multirow[t]{4}{*}{1.14} \\
\hline & & & 0.21 & 11 & 3.6 & & & \\
\hline & & & 0.48 & 93 & 69.2 & & & \\
\hline & & & 0.09 & 203 & 26.6 & & & \\
\hline & & \multirow[t]{4}{*}{3} & 0.14 & 1.5 & 0.3 & \multirow[t]{4}{*}{73} & \multirow[t]{4}{*}{122} & \multirow[t]{4}{*}{1.16} \\
\hline & & & 0.23 & 11 & 3.5 & & & \\
\hline & & & 0.53 & 94 & 68.4 & & & \\
\hline & & & 0.10 & 206 & 27.8 & & & \\
\hline & & \multirow[t]{4}{*}{13} & 0.16 & 2.5 & 0.5 & \multirow[t]{4}{*}{72} & \multirow[t]{4}{*}{123} & \multirow[t]{4}{*}{0.99} \\
\hline & & & 0.23 & 12 & 3.8 & & & \\
\hline & & & 0.51 & 94 & 66.2 & & & \\
\hline & & & 0.10 & 204 & 29.4 & & & \\
\hline \multirow[t]{12}{*}{2} & \multirow{12}{*}{$\begin{array}{c}\text { Pep }+ \text { WT } \\
+ \text { salt }\end{array}$} & \multirow[t]{4}{*}{1} & 0.24 & 1.9 & 0.7 & \multirow[t]{4}{*}{64} & \multirow[t]{4}{*}{126} & \multirow[t]{4}{*}{1.18} \\
\hline & & & 0.23 & 11 & 3.9 & & & \\
\hline & & & 0.43 & 94 & 63.1 & & & \\
\hline & & & 0.10 & 204 & 32.4 & & & \\
\hline & & 3 & 0.17 & 2.8 & 0.7 & 73 & 127 & 1.09 \\
\hline & & & 0.23 & 13 & 4.0 & & & \\
\hline & & & 0.48 & 94 & 62.2 & & & \\
\hline & & & 0.12 & 205 & 33.1 & & & \\
\hline & & 13 & 0.16 & 1.8 & 0.4 & 68 & 127 & 1.03 \\
\hline & & & 0.28 & 11 & 4.3 & & & \\
\hline & & & 0.40 & 88 & 51.8 & & & \\
\hline & & & 0.16 & 185 & 43.5 & & & \\
\hline 3 & Pep + WT & 1 & 0.24 & 4.3 & 1.2 & 86 & 136 & 1.08 \\
\hline & + det & & 0.16 & 20 & 3.9 & & & \\
\hline & & & 0.47 & 121 & 66.3 & & & \\
\hline & & & 0.13 & 191 & 28.6 & & & \\
\hline & & 4 & 0.24 & 3.9 & 1.2 & 81 & 131 & 1.15 \\
\hline & & & 0.17 & 20 & 4.2 & & & \\
\hline & & & 0.49 & 119 & 71.4 & & & \\
\hline & & & 0.10 & 195 & 23.3 & & & \\
\hline & & 10 & 0.21 & 3.4 & 0.8 & 82 & 133 & 1.12 \\
\hline & & & 0.21 & 16 & 4.1 & & & \\
\hline & & & 0.48 & 119 & 70.0 & & & \\
\hline & & & 0.11 & 193 & 25.2 & & & \\
\hline 4 & Pep + DDD & 1 & 0.14 & 2.6 & 0.5 & 73 & 109 & 1.10 \\
\hline & & & 0.19 & 13 & 3.3 & & & \\
\hline & & & 0.62 & 96 & 81.2 & & & \\
\hline & & & 0.06 & 201 & 15.0 & & & \\
\hline & & 4 & 0.17 & 2.3 & 0.5 & 69 & 106 & 1.13 \\
\hline & & & 0.18 & 13 & 3.3 & & & \\
\hline & & & 0.60 & 93 & 81.3 & & & \\
\hline & & & 0.05 & 201 & 14.8 & & & \\
\hline & & 10 & 0.15 & 1.9 & 0.4 & 69 & 107 & 1.11 \\
\hline & & & 0.20 & 12 & 3.5 & & & \\
\hline & & & 0.59 & 93 & 80.0 & & & \\
\hline & & & 0.06 & 201 & 16.8 & & & \\
\hline
\end{tabular}

${ }^{a}$ Abbreviations: Pep, peptide-pyrene conjugate; WT, wild-type gp96; salt, $\mathrm{KCl}, 750 \mathrm{mM}$; det, zwittergent 3-12, $5 \mathrm{mM}$; DDD, dimerization deletion mutant protein; $\delta$ days, number of days the sample was incubated at $4{ }^{\circ} \mathrm{C}$ starting on day $1 .{ }^{b}$ Amplitudes normalized to a sum of $1 .{ }^{c}$ The percent contribution of each exponential component to the total fluorescence intensity: $100 \alpha_{i} \tau_{i} / \sum \alpha_{i} \tau_{i .}{ }^{d}$ The number-average lifetime: $\sum \alpha_{i} \tau_{i} / \sum \alpha_{i .}{ }^{e}$ The intensity-weighted lifetime: $\sum \alpha_{i} \tau_{i}{ }^{2} / \sum \alpha_{i} \tau_{i}{ }^{f} \mathrm{~A}$ measure of the goodness of fit.

Stability of Peptide-gp96 Complexes. We also assessed the stability of the complexes by monitoring lifetime decay parameters of the complexes over a long period of time (Table 2). The same sample was used to collect decay curves following complex formation (on day 1) and after long-term incubation in the refrigerator. Over this time, there was almost no perturbation of the intensity-averaged lifetime $\langle\tau\rangle$ for any sample, indicating that gp96-peptide complexes were extraordinarily stable (Table 2). The WT gp96-peptide complexes were challenged with $750 \mathrm{mM} \mathrm{KCl}$ (sample 2, Table 2) or with the detergent zwittergent 3-12 (sample 3, 
Table 3: Gel Filtration HPLC Profile of gp96 WT and Dimerization Mutant Peptide-Pyrene Complexes ${ }^{a}$

\begin{tabular}{llccll}
\hline sample & peak 1 & peak 2 & peak 3 & peak 4 & peak 5 \\
\multicolumn{5}{c}{ WT gp96 + Peptide } \\
retention (min) & 4.1 & 6.1 & 7.5 & 7.7 & 9.8 \\
F396 nm (cps) & 73327 & 205267 & 311463 & 94094 & 109249 \\
\multicolumn{5}{c}{ DDD gp96 + Peptide } \\
retention (min) & 5.0 & 5.4 & 6.6 & 7.0 \\
F396 nm (cps) & 63425 & 66199 & 36837 & 29013 \\
\hline
\end{tabular}

${ }^{a}$ The peaks are described in terms of retention times $(\mathrm{min})$ in the HPLC gel filtration column. F396 nm is the pyrene fluorescence emission signal at $396 \mathrm{~nm}$ from peptide-pyrene in counts per second (cps). The excitation was at $330 \mathrm{~nm}$.

Table 2). Neither high salt nor the detergent appeared to disrupt the complexes over a period of $\sim 10$ days. It has been reported that the detergent zwittergent 3-12 disrupts gp96 dimers to produce monomers (32). If the effect of deletion of the dimerization domain is only to produce more gp96 monomers compared to WT gp96, then the detergent effects should mimic the deletion mutation. This was clearly not the case (Table 2). Thus, there appears to be more to the role of the dimerization domain. The intensity-averaged lifetime $\langle\tau\rangle$ was slightly higher in the presence of the detergent (compare sample 3 with sample 1 in Table 2). Because the detergent produces monomers of the WT protein (32), our results indicate that the peptide-binding environment in monomers may be somewhat different from the one in dimers (or higher order forms).

To demonstrate further that gp96-peptide complexes are stable, the same samples that had been used to collect the intensity decay data (Table 2) were subjected to HPLC gel filtration chromatography. Following chromatography, all of the complexes contained fluorescent peptide (F396 nm; Table 3 ), indicating that the bound peptide was quite stable to HPLC. Together, the HPLC profile and fluorescence data indicate that the higher order complexes, at least up to hexamers and octamers of both WT and DDD, do bind peptides. The retention times of WT complexes were distinct from the times of DDD mutant complexes, suggesting that WT and DDD complexes may have different shapes and/or sizes, a fact that is consistent with STEM (Figure 3). To further test the stability of the complexes, the complexes in the major peaks (peak 1 from WT complexes and peaks 2 and 3 from the DDD mutant complex; Table 3) were rechromatographed using the same HPLC method. Greater than $80-90 \%$ of the peak area and fluorescence intensity was recovered at the same retention time in the second round of HPLC (not shown). This indicated that the complexes were extremely stable and that, once the peptide was bound, it does not have to be in equilibrium with excess free peptide (dissociation cannot be entirely due to mass action).

\section{DISCUSSION}

In this work, we have investigated the effects of the socalled dimerization domain of gp96 (GRP94) on the higher order quaternary structure of gp96 and peptide binding. Previous workers have reported that WT gp96 (GRP94) existed as an obligatory tail-to-tail extended, rodlike dimer $(32,51)$. More recently, we have shown that the high-affinity peptide-binding site in gp96 abuts the dimerization domain (29). This model begged the question, does the dimerization domain influence peptide loading by gp96? To address this question, we constructed a mutant form of His-tagged mouse gp96 protein lacking the dimerization domain. This mutant protein by itself displayed some interesting properties relative to the WT protein, which indicated that the dimerization domain played a role in the structural organization and stability of the gp96-peptide complexes.

Dynamic light scattering, HPLC gel filtration, and equilibrium analytical ultracentrifugation all indicated that WT gp96 formed large homooligomeric aggregates (Figure 2). Interestingly, the DDD mutant gp96 protein also formed higher order quaternary structures (Figures 2 and 3). Detailed examination by STEM revealed a plethora of aggregate shapes and sizes (Figure 3). The most frequent WT structure was a basic dimer unit, in agreement with previous studies $(27,32)$. However, monomers as well as trimers and tetramers to octamers were also quite abundant (Figure 3B). The DDD mutant showed more or less equal frequencies of monomer to tetramer units and many larger species (Figure 3 ). These findings are surprising and novel because they suggest additional site(s) for subunit interaction besides the dimerization domain. Whereas our results support and extend the previous work (32), there are some important differences in the techniques used here compared to those used by others (32), which could explain some of the divergent results. These authors purified gp96 from ER microsomes in the presence of nonionic detergent $(32,52)$. It is possible that large native aggregates were disrupted by these conditions. The EM study in the previous work (32) was also done with samples that were first purified by density-gradient ultracentrifugation, which may have enriched the samples for aggregates containing the fewest protomers. The previous study (32) used rotary-shadowing EM, whereas we used the gentler STEM. The STEM looks at "bare" molecules, whereas with rotary shadowing, they are coated with grains (even if small) of metal. With shadowing, no masses are obtainable and it is rather difficult to determine the dimensions.

It is unlikely that the His tag in our protein causes aggregation because native mouse gp96 protein also aggregated. The KDEL motif is probably not the cause of aggregation; it has never been reported to cause selfassociation of peptides or proteins (53). On the other hand, many chaperones and chaperonins exist as native massive homooligomeric aggregates. For example, hsp60, groEL, and Rubisco-binding protein are in 14-mer complexes (e.g., see refs 54 and 55). The archaebacterial chaperone TF- 55 exists as a stacked-ring complex of molecular mass $>1000 \mathrm{kDa}$ consisting of 16-18 monomer units (56). In addition, HSP70, smHSPs, and HSP40 can be found in large and variably sized granular aggregates in vivo under conditions of stress (57). Intuitively, formation of large homomultimers should require more than one site for self-association. Our results (Figures 2 and 3) are in broad agreement with analogous observations with other chaperones. However, gp96 might be especially prone to dissociation and/or aggregation, making the detection of a unique species of large homomultimer extremely difficult. Alternatively, gp96 may naturally exist in multiple aggregated states.

The DDD mutant protein appeared to be in a more compact form than the WT protein. This conclusion was borne out by analysis using $\mathrm{CD}$, intrinsic Trp fluorescence, and STEM (Figures 2, 3, and 7). Specifically, CD appeared 
to show that the DDD mutant protein has an altered conformation. This is apparently not due to global misfolding or unfolding of the mutant protein because it can be purified in large amounts, is stable, and binds the peptide with only a small difference in $K_{\mathrm{d}}$ compared to that of the WT protein (Figure 6). The intriguing question is, how does deletion of one stretch of 45 amino acids in the $\mathrm{C}$-terminal region so dramatically affect the overall folded structure of the remainder of the protein? Clearly, this effect is not like a classic case of conformational change brought on by breaking disulfide bonds because of mutation (58). There are no known disulfides in gp96, and no Cys residues were deleted from the DDD mutant. By deleting the dimerization domain, which is hydrophobic (32), a significant change in the secondary structure (CD) and the tertiary structure (Trp fluorescence) occurred. A likely scenario is that deletion of this hydrophobic domain necessitated local repacking of the interior of the protein, which affected a Trp residue(s) $\mathrm{N}$ terminal to the deletion. Dramatic changes in protein conformation can be expected as a result of the deletion of amino acids from the interior of a protein.

The peptide-binding affinity $\left(K_{\mathrm{d}}\right)$ of the DDD mutant is only moderately different from that of the WT gp96 (Figure 6 ), which suggests that the affinity of the mutant protein for the peptide is only slightly affected. This finding is not surprising in the view of our peptide-binding site model: the minimal contact region for the bound peptide, i.e., for the modified Lys residue in the bound peptide, lies at the opposite end of the peptide-binding groove as the dimerization domain (29). However, because the peptide is bound in a dimer or other higher order structures (Figure 3) and the dimerization domain abuts the peptide-binding site (29), there could be indirect effects on the microenvironment of the bound peptide because of the deletion of the dimerization domain. This was clearly demonstrated by time-resolved fluorescence spectroscopy (Figure 8). Alternatively, the change in the peptide environment may be related to the conformational change in the overall secondary/tertiary structure of the DDD mutant, as is observed in the CD/Trp fluorescence spectra. These changes may include repacking and conformational alterations of neighboring segments of the peptide-binding pocket. There was no hindrance to rapid (unmeasurable) depolarizing motions of the pyrene probe, indicating ample free space in the peptide-binding pocket. This is consistent with the peptide-binding pocket model, in which the modified Lys was shown pointing away from the nearest gp96 $\alpha$ helix (29).

Collectively, our findings suggest that there is a certain degree of functional plasticity associated with the organization of the peptide-binding pocket of gp96. Plasticity, combined with the notion that the peptide-binding pocket may be open-ended (29), may explain why gp96 can bind a large array of peptides of different amino acid sequences and sizes (e.g., see ref 28). The free space in the binding pocket, as indicated by the fluorescence anisotropy decay studies, may permit the accommodation of different amino acid side chains.

Implications for Immunogenicity of gp96-Peptide Complexes. In accordance with current models of the immuneresponse pathway, macrophages or dendritic cells internalize gp96- peptide complexes through receptor-mediated mechanisms $(19,20,62)$. Their peptide cargo is transferred to and represented by MHC class I molecules, which may stimulate a $\mathrm{T}$ cell response (ref 21, 59; see the introduction). If this mechanism is correct, it suggests that peptide-gp96 complexes can relocate from their original site of formation within the ER lumen to a different site or subcellular compartment in a specialized antigen-presenting cell. For the faithful relay of gp96-bound peptides to MHC class molecules or other relay partners and for downstream events to occur, gp96-peptide complexes must be stable for extended periods of time. Furthermore, complex stability cannot depend solely on equilibrium-driven peptide binding because an excess of free peptides is probably unavailable during transit or at the new location. Our data show that gp96peptide antigen complexes are indeed extraordinarily stable (Tables 2 and 3) and that the assembly domain improves peptide-gp96 complex stability and contributes to its structure. These properties of the gp96-peptide complexes lend support to the theory that peptide antigens carried by gp96 can withstand spatial and temporal transport, which are likely to be part of the gp96 immune response pathway. Furthermore, under the assumption that peptides are transferred from gp96 to molecules such as cochaperones and/or MHC molecules, the existence of multiple conformers, plasticity, and rotational freedom in the gp96-peptide complexes, as documented here (Figure 3 and Tables 2 and 3), could serve to broaden the spectrum of molecular recognition.

\section{ACKNOWLEDGMENT}

We thank Drs. Pramod Srivastava and Sreyashi Basu for the gift of native mouse gp96 and of the bacterial strain containing plasmid pZ010, which was constructed by Dr. Z. Li. We thank Dr. Michael Goger (spectroscopy facility at The Rockefeller University) for making available the CD spectrometer. We are grateful to Dr. Joseph S. Wall (Brookhaven National Laboratory, BNL) for the PC mass program for STEM image analysis. The BNL STEM is a National Institutes of Health (NIH)-supported resource center with additional support provided by U.S. Department of Energy, Office of Biological and Environmental Research. The mass spectrometry laboratory at The Rockefeller University is a NIH-supported biomedical resource center.

\section{REFERENCES}

1. Turley, S. J., Inaba, K., Garrett, W. S., Ebersold, M., Unternaerer, J., Steinman, R., and Mellman, I. (2000) Science 288, 522-527.

2. York, I. A., and Rock, K. L. (1996) Annu. Rev. Immunol. 14, 369-396.

3. Hansen, T. H., and Lee, D. R. (1997) Adv. Immunol. 64, 105137.

4. Jensen, P. E. (1997) Biopolymers 43, 303-322.

5. Srivastava, P. K., Menoret, A., Basu, S., Binder, R. J., and McQuade, K. L. (1998) Immunity 8, 657-665.

6. Mizzen, L. (1998) Biotherapy (Dordrecht, Neth.) 10, 173189

7. Hartl, F. U. (1996) Nature (London) 381, 571-580.

8. Csermely, P., Schnaider, T., Soti, C., Prohaszha, Z., and Nardai, G. (1998) Pharmacol. Ther. 79, 129-168.

9. Basu, S., and Srivastava, P. K. (1999) J. Exp. Med. 189, 797802 .

10. Nair, S., Wearsch, P. A., Mitchell, D. A., Wassenberg, J. J., Gilboa, E., and Nicchitta, C. V. (1999) J. Immunol. 162, 64266432.

11. Udono, H., and Srivastava, P. K. (1994) J. Immunol. 152, 5398-5403. 
12. Tamura, Y., Peng, P., Liu, K., Daou, M., and Srivastava, P. K. (1997) Science 278, 117-120.

13. Nieland, T. J., Tan, M. C., Monne-van Muijen, M., Koning, F., Kruisbeek, A. M., and van Bleek, G. M. (1996) Proc. Natl. Acad. Sci. U.S.A. 93, 6135-6139.

14. Heikema, A., Agsteribbe, E., Wilschut, J., and Huckriede, A. (1997) Immunol. Lett. 57, 69-74.

15. Blachere, N. E., Li, Z., Chandawarkar, R. Y., Suto, R., Jaikaria, N. S., Basu, S., Udono, H., and Srivastava, P. K. (1997) J. Exp. Med. 186, 1315-1322.

16. Udono, H., Levey, D. L., and Srivastava, P. K. (1994) Proc. Natl. Acad. Sci. U.S.A. 91, 3077-3081.

17. Suto, R., and Srivastava, P. K. (1995) Science 269, 15851588.

18. Arnold, D., Faath, S., Rammensee, H., and Schild, H. (1995) J. Exp. Med. 182, 885-889.

19. Arnold-Schild, D. D., Hanau, D., Spehner, D., Schmid, C., Rammensee, H.-G., de la Salle, H., and Schild, H. (1999) J. Immunol. 162, 3757-3760.

20. Wassenberg, J. J., Dezfullian, C., and Nicchitta, C. V. (1999) J. Cell Sci. 112, 2167-2175.

21. Srivastava, P. K., Udono, H., Blachere, N. E., and Li, Z. (1994) Immunogenetics 39, 93-98.

22. Li, Z., and Srivastava, P. K. (1993) EMBO J. 12, 3143-3151.

23. Lammert, E., Arnold, D., Nijenhuis, M., Momburg, F., Hammerling, G. J., Brunner, J., Stevanovic, S., Rammensee, H. G., and Schild, H. (1997) Eur. J. Immunol. 27, 923927.

24. Spee, P., and Neefjes, J. (1997) Eur. J. Immunol. 27, 24412449.

25. Wearsch, P. A., and Nicchitta, C. V. (1997) J. Biol. Chem. 272, 5152-5156.

26. Breloer, M., Marti, T., Fleischer, B., and von Bonin, A. (1998) Eur. J. Immunol. 28, 1016-1021.

27. Sastry, S., and Linderoth, N. (1999) J. Biol. Chem. 274, $12023-12035$

28. Ishii, T., Udono, H., Yamano, T., Ohta, H., Ono, T., Hizuta, A., Tanaka, N., Srivastava, P. K., and Nakayama, E. (1999) J. Immunol. 162, 1303-1309.

29. Linderoth, N. A., Popowicz, A., and Sastry, S. S. (2000) J. Biol. Chem. 275, 5472-5477.

30. Arnold, D., Wahl, C., Faath, S., Rammensee, H. G., and Schild, H. (1997) J. Exp. Med. 186, 461-466.

31. Marusina, K., Reid, G., Gabathuler, R., Jefferies, W., and Monaco, J. J. (1997) Biochemistry 36, 856-863.

32. Wearsch, P. A., and Nicchitta, C. V. (1996) Biochemistry 35, 16760-16769.

33. Beavis, R. C., and Chait, B. T. (1996) Methods Enzymol. 270, 519-551.

34. Sastry, S. S., and Ross, B. M. (1997) Biochemistry 36, $3133-$ 3144.

35. Chen, G. C., and Yang, J. T. (1977) Anal. Chem. 10, 11951207.

36. Cantor, C. R., and Schimmel, P. (1980) Biophysical Chemistry, Vol. II, pp 627-632, W. H. Freeman, San Francisco, CA.
37. Wall, J. S., Hainfeld, J. F., and Simon, M. N. (1998) Methods Cell Biol. 53, 139-166.

38. Lakowicz, J. R. (1983) Principles of fluorescence spectroscopy, pp 171-178 and 347-357, Plenum Press, New York.

39. Hasselbacher, C. A., Waxman, E., Galati, L. T., Contino, P. B., Ross, J. B. A., and Laws, W. R. (1991) J. Phys. Chem. 95, 2995-3005.

40. Grinvald, A., and Steinberg, I. Z. (1974) Anal. Biochem. 59, 583-598.

41. Bevington, P. R. (1969) Data reduction and error analysis for the physical sciences, pp 204-246, McGraw-Hill, New York.

42. Mazzarella, R., and Green, M. (1987) J. Biol. Chem. 262, 8875-8883.

43. Prodromou, C., Roe, S. M., O’Brien, R., Ladbury, J. E., Piper, P. W., and Pearl, L. H. (1997) Cell 90, 65-75.

44. Zhang, W., Young, A. C. M., Imarai, M., Nathenson, S. G., and Sacchettini, J. C. (1992) Proc. Natl. Acad. Sci. U.S.A. 89, 8403-8407.

45. Knopp, J. A., and Weber, G. (1969) J. Biol. Chem. 244, 63096315.

46. Barrantes, F. J., Sakmann, B., Bonner, R., Eibl, H., and Jovin, T. M. (1975) Proc. Natl. Acad. Sci. U.S.A. 72, 3097-3101.

47. Gorovits, B. M., and Horowitz, P. M. (1995) J. Biol. Chem. 270, 13057-13062.

48. Feng, L., Kim, E., Lee, W. L., Miller, C. J., Kuang, B., Reisler, E., and Rubenstein, P. A. (1997) J. Biol. Chem. 272, 1682916837.

49. Winnik, F. M. (1993) Chem. Rev. 93, 587-614.

50. Bialik, C. N., Wolf, B., Rachofsky, E. L., Ross, J. B. A., and Laws, W. R. (1998) Biophys. J. 75, 2564-2573.

51. Koyasu, S., Nishida, E., Miyata, Y., Sakai, H., and Yahara, I. (1989) J. Biol. Chem. 264, 15083-15087.

52. Wearsch, P. A., and Nicchitta, C. V. (1996) Protein Expression Purif. 7, 114-121.

53. Vaux, D., Tooze, J., and Fuller, S. (1990) Nature (London) $345,495-502$.

54. Hendrix, R. J. W. (1979) J. Mol. Biol. 129, 359-373.

55. McMullen, T. W., and Heidelberg, R. L. (1988) Mol. Cell Biol. 8, 371-380.

56. Trent, J. D., Nimmesgern, E., Wall, J. S., Ulrich-Hartl, F., and Horwich, A. L. (1991) Nature (London) 354, 490-493.

57. Smykal, P., Hrdy, I., and Pechan, P. M. (2000) Eur. J. Biochem. 267, 2195-2207.

58. Creighton, T. E. (1988) Science 240, 267-344.

59. Nicchitta, C. V. (1998) Curr. Opin. Immunol. 10, 103-109.

60. Saxena, V. P., and Wetlaufer, D. B. (1971) Proc. Natl. Acad. Sci. U.S.A. 68, 969-972.

61. Srivastava, P. K. (1997) Methods 12, 165-171.

62. Binder, R. J., Han, D. K. and Srivastava, P. K. (2000) Nat. Immunol. 1, 151-153.

63. Cadene, M., and Chait, B. T. (2000) Anal. Chem. 72, $5655-5658$

BI0016218 